\title{
Helicobacter pylori infection in Chinese patients with atrial fibrillation
}

This article was published in the following Dove Press journal:

Clinical Interventions in Aging

28 April 2015

Number of times this article has been viewed

\author{
De-Zhao Wang' \\ Wei Chen' \\ Song Yang ${ }^{2}$ \\ Jun Wang ${ }^{3}$ \\ Qun Li' \\ Qiang Fu \\ Shi-Jing $\mathrm{Li}^{3}$ \\ Bu-Xing Chen' \\ 'Department of Cardiology, \\ Beijing Tiantan Hospital, Capital \\ Medical University, ${ }^{2}$ Department \\ of Ultrasonography, Beijing Tiantan \\ Hospital, Capital Medical University, \\ ${ }^{3}$ Department of Cardiology, Beijing \\ Mentougou District Hospital, Beijing, \\ People's Republic of China
}

\begin{abstract}
Objective: To explore the relationship between Helicobacter pylori $(\mathrm{Hp})$ infection and atrial fibrillation (AF) in Chinese patients.

Methods: A total of 285 hospitalized patients with AF and 300 patients from Health Screening Center who matched age and sex with AF group were enrolled. AF patients were divided into two groups: the short-standing AF category (less than a year) and the long-standing AF category (more than a year). All patients had laboratory testing of ${ }^{13} \mathrm{C}$ urea breath test, high-sensitive C-reactive protein (hs-CRP) and left atrial diameter (LAD). We analyzed the difference of these factors in all groups and explored the correlation between Hp infection and AF using logistic regression analysis.
\end{abstract}

Results: Both AF groups had more hypertension, diabetes, and Hp infection than the control group. The Hp value and the hs-CRP level in patients with long-standing AF were higher than those in the short-standing AF and the control groups (for Hp value: $P<0.001$ for both and for hs-CRP level: $P=0.003,0.002$, respectively). The LAD of patients in the long-standing AF group was significantly larger than those in the short-standing AF group and control group $(P=0.001$ and $P<0.001$, respectively). The values of Hp, hs-CRP, and LAD in the long-standing AF category were significantly higher than those in the short-standing AF category (all $P<0.05$ ). After controlling the potential confounders, Hp value $\geq 4 \%$, hs-CRP $>5 \mathrm{mg} / \mathrm{L}$, and LAD $>36 \mathrm{~mm}$ were significantly related to long-standing AF.

Conclusion: The values of $\mathrm{Hp}$ in patients with long-standing AF were significantly higher than those in short-standing AF and control groups. Hp $\delta$ value $\geq 4 \%$ is an independent predictor for long-standing AF.

Keywords: high sensitivity C-reactive protein, left atrial diameter, ${ }^{13} \mathrm{C}$ urea breath test

\section{Introduction}

Atrial fibrillation (AF) is one of the most common clinical arrhythmias and easily complicated by cardiac insufficiency and thromboembolic complications, which seriously affect the patients' quality of life. The occurrence and maintenance mechanism of AF is not very clear at present. Some studies reported that the structural and electrophysiological basis of the occurrence of AF might be the left atrial reentrant micro ring and enlarged left atrium. ${ }^{1}$ Some researchers found that elevated plasma high-sensitive C-reactive protein (hs-CRP) level was an independent risk factor for AF, which indicated that chronic inflammation seemed to play an important role in the development of $\mathrm{AF}^{2}$ A study from the digestion department of internal medicine (Beijing Mentougou District Hospital, Beijing China) showed that the Helicobacter pylori (Hp) infection rate was as high as $50 \%$ in Chinese adults, and Hp was not only an important pathogenic reason for chronic gastritis and stomach cancer but also closely related to the occurrence of non-gastrointestinal diseases. ${ }^{3}$
De-Zhao Wang

Department of Cardiology, Beijing

Tiantan Hospital, Capital Medical

University, No 6, Tiantan Xili, Dongcheng

District, Beijing 100050, People's

Republic of China

Tel +86 I0 6709 6572; +86 I0 67096577

Email chbux@।26.com; docwdz@।63.com 
Some studies showed that chronic Hp infection was involved in $\mathrm{AF}$ and it played an important role in the development of $\mathrm{AF}^{4-8}$ but others demonstrated that $\mathrm{Hp}$ infection was not correlated with AF. ${ }^{9-11}$ However, these studies had relatively small sample sizes, and none of the patients have been classified into different AF-type categories in accordance with the guidelines to further explore the correlation between Hp infection and different types of AF. The purpose of this study was to clarify the relationship between $\mathrm{Hp}$ infection and the different types of $\mathrm{AF}$, and to investigate the occurrence and maintenance mechanism of AF.

\section{Materials and methods Subjects}

This study consisted of a retrospective analysis of a singlesite cohort. The consecutive hospitalized patients with AF (excluding cardiac insufficiency, acute coronary syndrome, thyroid dysfunction, and any infections) in Beijing Tiantan Hospital from January 1, 2007 to April 12, 2013 were selected. The control group came from Health Screening Center during the same period, and their age and sex matched those of the AF group. Subjects who had suffered gastrointestinal bleeding within 1 week; had a history of gastrectomy; used antibiotics, bismuth, or sucralfate within 1 month; had a chronic infection; had obesity; had heart failure; or had other conditions that might increase IL- 6 promoting chronic inflammatory response were excluded. There were 110 males (38.6\%) and 175 females (61.4\%). Patient history, physical examination, and laboratory results were recorded with chart abstraction. Their average age was $63.8 \pm 10.8$ years. Patients were divided into two groups: the short-standing AF group, in whom the symptoms persisted for less than 1 year, and the long-standing AF group, in whom the symptoms persisted for more than 1 year.

\section{Tests and examinations}

\section{Routine examination}

All the patients underwent the following tests/examinations on the next day after admission: blood routine, biochemical items, glycosylated hemoglobin, hs-CRP, homocysteine (HCY), ${ }^{13} \mathrm{C}$ urea breath, blood coagulation, and ultrasonic cardiogram (UCG).

\section{${ }^{13} \mathrm{C}$ urea breath test}

The ${ }^{13} \mathrm{C}$ urea breath test was measured using the HCBT-01 breath test automatic instrument (Shenzhen Zhonghe Haidewei Biological Technology Co. Ltd), and the determination whether patients had Hp infection was calculated by ${ }^{13} \mathrm{C} /{ }^{12} \mathrm{C}$ isotope ratio $(\delta \%)$. Subjects were asked to fast more than 2 hours before blood tests. The positive value of Hp infection was defined as $\delta \geq 4 \% \pm 0.4 \%$.

\section{Hs-CRP and Hp antibody level}

Hs-CRP was measured using particle-enhanced immune transmission turbidimetry (DiaSys Diagnostic Systems of GmbH). Hp-IgG antibody was measured by the colloidal gold method (Shanghai Enterasys Biological Technology Co. Ltd).

\section{UCG examination}

UCG examination was performed using the United States GE Vivid 7 ultrasound heartbeat graph diagnosis system. Patients were asked to be in the left lateral position. The parasternal long axis, parasternal short axis, apical four-chamber view, and apical two-chamber view were used. Left ventricular end-diastolic diameter and left atrial diameter (LAD) were measured by using the parasternal long axis view. Biplane Simpson formula was used to quantify left ventricular ejection fraction.

\section{Statistical methods}

Baseline characteristics of patients were compared using ANOVA for continuous variables and the chi-squared test for non-continuous variables. When continuous data were not normally distributed, groups were compared using nonparametric Wilcoxon rank sum test. The correlation between baseline characteristics and long-standing AF was tested using a univariate logistic regression model. Clinically significant variables were entered into a multivariate regression model. $P<0.05$ was statistically significant. Statistical analysis was performed using the SPSS software (version 13.0).

\section{Results}

\section{The baseline data of each group}

Control group had 300 (51.3\%) patients, short-standing AF group had $126(21.5 \%)$ patients, and long-standing AF group had $159(27.2 \%)$ patients. The baseline data of each group are shown in Table 1. There were significant differences in age, heart rate (HR), neutrophils (NEU), LAD, hs-CRP, and $\mathrm{HCY}$ among the groups. Patients with long-standing AF were older and had a higher value of HR, NEU, LAD, hs-CRP, and HCY than those with short-standing AF (Table 1).

There were significant differences in the incidence of Hp-negative and $\mathrm{Hp}-\mathrm{IgG}$ antibody negative $(65.0 \%$ vs $69.8 \%$ vs $12.0 \%, P<0.001)$ and $\mathrm{Hp}$-positive and $\mathrm{Hp}$-IgG antibody positive $(15.0 \%$ vs $18.3 \%$ vs $73.6 \%, P<0.001)$ among the groups (Figure 1). There were no significant differences in 
Table I The baseline data of each group

\begin{tabular}{|c|c|c|c|c|c|}
\hline \multirow[t]{2}{*}{ Group } & \multirow{2}{*}{$\begin{array}{l}\text { Control } \\
\text { group }(n=300)\end{array}$} & \multicolumn{3}{|l|}{ AF group } & \multirow[t]{2}{*}{$P$-value } \\
\hline & & $\begin{array}{l}\text { Short-standing AF } \\
\text { group }(n=126)\end{array}$ & $\begin{array}{l}\text { Long-standing AF } \\
\text { group }(n=159)\end{array}$ & $P$-value & \\
\hline Female, $n$ & $198(66.0 \%)$ & $82(65.1 \%)$ & $93(58.5 \%)$ & 0.256 & 0.265 \\
\hline Smoke, n & $159(53.0 \%)$ & $66(52.4 \%)$ & 81 (50.9\%) & 0.809 & 0.916 \\
\hline Alcohol, n & 89 (29.7\%) & $43(34.1 \%)$ & $54(34.0 \%)$ & 0.977 & 0.525 \\
\hline Hypertension, $n$ & $22 \mid(73.7 \%)$ & $99(78.6 \%)$ & $121(76.1 \%)$ & 0.622 & 0.546 \\
\hline Dyslipidemia, n & $112(37.3 \%)$ & 55 (43.7\%) & $62(39.0 \%)$ & 0.427 & 0.475 \\
\hline Diabetes mellitus, $\mathrm{n}$ & $90(30.0 \%)$ & $32(25.4 \%)$ & $54(34.0 \%)$ & 0.118 & 0.293 \\
\hline Cerebral infarction, $\mathrm{n}$ & $82(27.3 \%)$ & 37 (29.4\%) & $54(34 \%)$ & 0.408 & 0.334 \\
\hline Hematencephalon, n & $7(1.2 \%)$ & $5(0.9 \%)$ & $4(0.7 \%)$ & 0.486 & 0.628 \\
\hline Family history of $A F, n$ & $11(3.7 \%)$ & $7(5.6 \%)$ & $5(3.1 \%)$ & 0.314 & 0.550 \\
\hline Arteriosclerosis, $n$ & $190(63.3 \%)$ & $85(67.5 \%)$ & $116(73.0 \%)$ & 0.312 & 0.113 \\
\hline Fundus abnormal, $\mathrm{n}$ & $268(89.3 \%)$ & 112 (88.9\%) & I 35 (84.9\%) & 0.462 & 0.205 \\
\hline Mean age $\pm S D$ (years) & $60.2 \pm 10.65$ & $62.1 \pm 11.78$ & $65.1 \pm 9.80$ & 0.022 & $<0.001$ \\
\hline Mean SBP \pm SD $(\mathrm{mmHg})$ & $135 \pm 22.3$ & $132 \pm 23.1$ & $136 \pm 22.3$ & 0.235 & 0.478 \\
\hline Mean heart rate/minute & $74 \pm 12.3$ & $76 \pm 16.0$ & $79 \pm 14.5$ & 0.019 & $<0.001$ \\
\hline Mean WBC \pm SD $\left(10^{9} / \mathrm{L}\right)$ & $7.3 \pm 2.30$ & $7.4 \pm 2.50$ & $7.4 \pm 2.53$ & 0.851 & 0.919 \\
\hline Mean NEU \pm SD $\left(10^{9} / L\right)$ & $4.9 \pm 1.44$ & $5.3 \pm 1.60$ & $6.3 \pm 2.19$ & $<0.001$ & $<0.001$ \\
\hline Mean LVEF \pm SD (\%) & $61.4 \pm 10.13$ & $61.9 \pm 10.80$ & $60.8 \pm 10.55$ & 0.363 & 0.654 \\
\hline Mean LAD $\pm S D(m m)$ & $32.9 \pm 4.45$ & $34.8 \pm 4.79$ & $36.7 \pm 5.86$ & 0.001 & $<0.001$ \\
\hline Mean $\mathrm{BMI} \pm \mathrm{SD}\left(\mathrm{kg} / \mathrm{m}^{2}\right)$ & $25.5 \pm 3.88$ & $25.2 \pm 3.41$ & $25.4 \pm 4.16$ & 0.673 & 0.681 \\
\hline $\begin{array}{l}\text { Median hs-CRP (mg/L) } \\
\text { (interquartile range) }\end{array}$ & $8.00(5.34-12.00)$ & $8.00(4.87-13.29)$ & $12.60(7.60-24.00)$ & 0.002 & 0.003 \\
\hline $\begin{array}{l}\text { Median } \mathrm{HCY}(\mu \mathrm{mol} / \mathrm{L}) \\
\text { (interquartile range) }\end{array}$ & $9.90(4.57-16.10)$ & $11.90(9.76-17.20)$ & $12.60(10.12-20.10)$ & 0.005 & $<0.001$ \\
\hline Hp-lgG antibody & $|3|(43.7 \%)$ & $60(47.6 \%)$ & $79(49.7 \%)$ & 0.238 & 0.437 \\
\hline $\begin{array}{l}\text { Hp } \delta \text { value (\%o) } \\
\text { (interquartile range) }\end{array}$ & $6.25(2.10-13.30)$ & $7.00(2.10-14.50)$ & $19.00(8.00-26.00)$ & $<0.001$ & $<0.001$ \\
\hline Hp $\delta$ value $\geq 4 \%$ 。 & 86 (28.7\%) & 31 (24.6\%) & $130(81.8 \%)$ & $<0.001$ & $<0.001$ \\
\hline
\end{tabular}

Abbreviations: AF, atrial fibrillation; SD, standard deviation; SBP, systolic blood pressure; WBC, white blood-cell count; NEU, neutrophil; LVEF, left ventricular ejection fraction; LAD, left atrium diameter; BMI, body mass index; hs-CRP, high sensitive C-reactive protein; HCY, homocysteine; Hp, Helicobacter pylori.

the incidence of Hp-negative and $\mathrm{Hp}-\mathrm{IgG}$ antibody positive (7.7\% vs 5.6\% vs 6.3\%, $P=0.696)$ and Hp-positive and HpIgG antibody negative ( $18.1 \%$ vs $6.4 \%$ vs $16.5 \%, P=0.117)$ among the groups (Figure 1).

The Hp levels on admission were significantly higher in the long-standing AF group than in the short-standing AF group and control group $(P<0.001, P<0.001$, respectively; Table 1 and Figure 2).

\section{Comparison of Hp $\delta$ value, Hs-CRP, and $L A D$ among five groups of $A F$}

There was a significant difference in $\mathrm{Hp} \delta$ value among the five groups (Table 2$)$ of $\mathrm{AF}(P=0.034)$. Patients with permanent AF in Group 5 had a significantly higher Hp level than those in Group 1, 2, and 3 ( $P=0.005,0.012$, and 0.038, respectively); there was also a significant difference in hsCRP value among the five groups $(P=0.014)$. The median hsCRP value of Group 5 was significantly higher than those of Group 1,2 , and 3 ( $P=0.000,0.025$, and 0.006 , respectively).
The mean LAD value in Group 5 was significantly higher than those in Group 1, 2, 3, and 4 ( $P=0.001,0.010,0.014$, and 0.034 , respectively) (Table 2 ).

\section{Logistic regression analysis in patients with long-standing AF}

The effects of variables in the presence of long-standing AF were determined by univariate and multivariate logistic regression analyses. In univariate analysis, we identified potential variables (age, HR, NEU, LAD, hs-CRP, Hp $\delta$ value, and HCY) and analyzed them by a multivariate logistic regression model. In multivariate analysis, Hp infection (odds ratio [OR] 13.172, 95\% confidence interval [CI] 7.819-22.191, $P<0.001)$ was still an independent predictor of long-standing AF as well as NEU $(P<0.001)$, hs-CRP $(P=0.002)$, and HCY $(P<0.001)$ (Table 3$)$.

The Hosmer-Lemeshow goodness of fit test showed chisquare 8.203 , df 8 , and $P$-value 0.414 , and contingency table for Hosmer and Lemeshow test are shown in Table 4. 


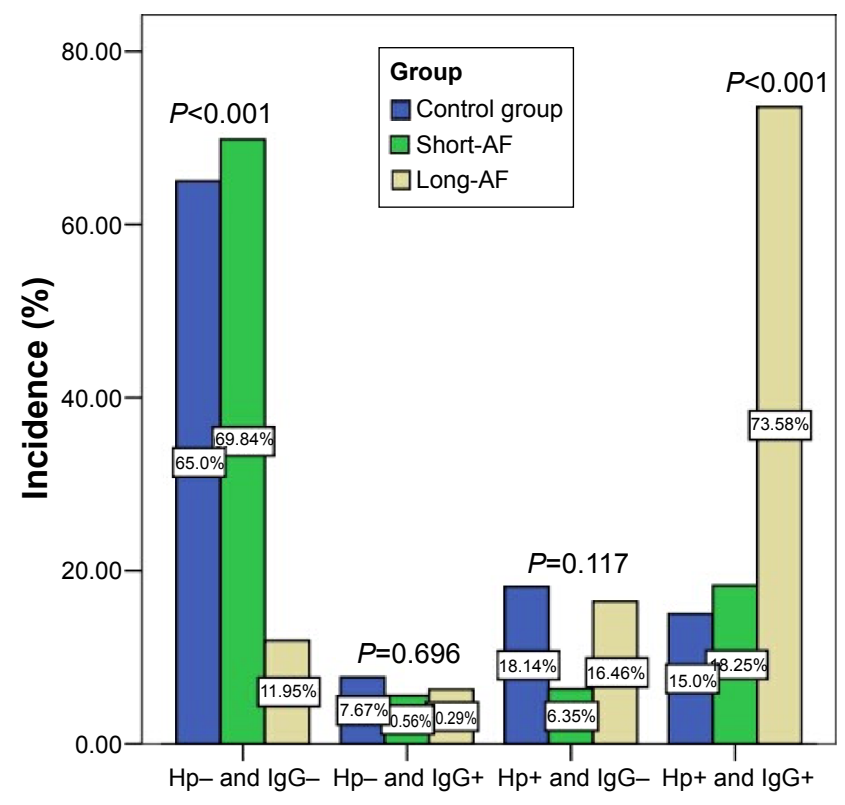

Figure I Comparison of Hp-positive/Hp-negative and Hp-lgG antibody-positive/ $\mathrm{Hp}$-IgG antibody-negative among the groups.

Abbreviations: $\mathrm{Hp}$, Helicobacter pylori; $\mathrm{AF}$, atrial fibrillation.

\section{Receiver-operating characteristic curves analysis of Hp infection, LAD, NEU, hs- $\mathrm{CRP}, \mathrm{HCY}$, and multivariate variables for predicting long-standing AF}

Hp $\delta$ value had a $66.7 \%$ sensitivity $(95 \%$ CI $0.733-0.801)$, $78.4 \%$ specificity ( $95 \%$ CI $0.751-0.817$ ), and the best critical value (14.75\%) in predicting long-standing $\mathrm{AF}$ (area under the curve [AUC] 0.774, Figure 3 and Table 5). LAD, NEU, hs-CRP, HCY, and multivariate variables for predicting longstanding AF are shown in Figure 3 and Table 5.

\section{Discussion}

Research about AF began in the last century, but the mechanism of AF still has not been completely clarified to date. In recent years, with the continuous research of chronic Hp infection, the correlation between Hp and nongastrointestinal diseases gradually entered people's field

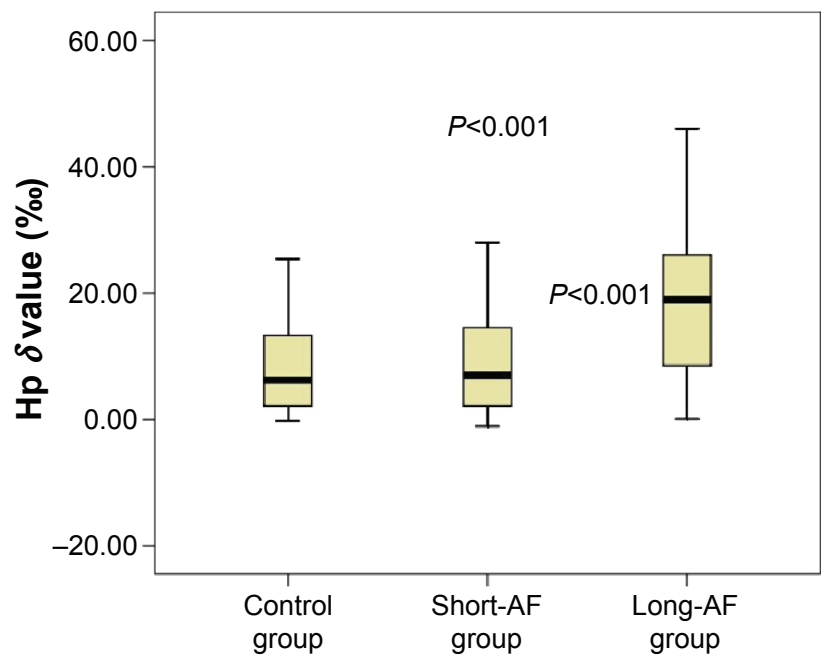

Figure 2 Comparison of $\mathrm{Hp}$ levels among the groups $(P<0.00 \mathrm{I})$.

Notes: The Hp levels on admission were significantly higher in the long-standing AF group than in the short-standing AF group and control group $(P<0.001, P<0.001$, respectively).

Abbreviations: $\mathrm{Hp}$, Helicobacter pylori; AF, atrial fibrillation.

of vision, especially the relationship between $\mathrm{Hp}$ and AF. However, the researchers have not reached an agreement. For example, a case-control study from Montenero in Italy showed that there was a strong correlation between chronic $\mathrm{AF}$ and Hp infection, ${ }^{6}$ but Lunetta et al did not find correlation between them in Italy population. ${ }^{9}$ Furthermore, most of these studies had no further classification for AF. Moreover, some studies only reported the relationship between Hp-IgG antibody and AF. There are great limitations to analyze the correlation between AF and plasma Hp-IgG antibody instead of $\mathrm{Hp}$ value, because the positive Hp-IgG antibody only shows that a patient has been infected with Hp previously and it does not reflect the situation in the patient with AF episode. Also, the sensitivity and specificity of $\mathrm{Hp}-\mathrm{IgG}$ antibody for coronary heart disease are poor. ${ }^{10}$

Considering the exposure of $\mathrm{Hp}$ in different ways, this study conducted a subgroup analysis and categorized the individuals as Hp-negative (by both tests), Hp-positive (by both tests), previous Hp (Hp antibody-positive) but not

Table 2 Comparing Hp $\delta$ value, hs-CRP, and LAD among five groups of AF

\begin{tabular}{|c|c|c|c|c|c|}
\hline Group & Types of AF & $\mathbf{n}$ & Hp $\delta$ value (\%o) & hs-CRP (mg/L) & $L A D \pm S D(m m)$ \\
\hline I & Initial AF & 34 & $6.35(1.8-11.4)^{*}$ & $4.30(\mathrm{I} .84-8.0 \mathrm{I})^{\#}$ & $35.9 \pm 3.80^{4}$ \\
\hline 2 & Paroxysmal AF & 58 & $5.25(1.67-19.3)^{*}$ & $5.58(3.89-10.27)^{\#}$ & $37.1 \pm 4.64^{\Perp}$ \\
\hline 3 & Persistent AF & 67 & $8.40(2.50-19.0)^{*}$ & $4.94(2.50-I I .56)^{\#}$ & $37.3 \pm 4.54^{\Perp}$ \\
\hline 4 & Long persistent $\mathrm{AF}$ & 76 & $8.10(2.43-30.4)$ & $5.83(2.36-\mid 4.4 I)$ & $37.6 \pm 5.16^{4}$ \\
\hline 5 & Permanent AF & 50 & $14.9(4.13-31.0)^{*}$ & $6.81(5.25-16.68)^{\#}$ & $39.5 \pm 5.75^{\wedge}$ \\
\hline
\end{tabular}

Notes: *Patients with permanent AF in Group 5 had a significantly higher Hp level than those in Group I, 2, and 3. "The median hs-CRP value of Group 5 was significantly higher than those of Group I, 2, and 3. ${ }^{4}$ The mean LAD value in Group 5 was significantly higher than those in Group I, 2, 3, and 4.

Abbreviations: Hp, Helicobacter pylori; hs-CRP, high sensitive C-reactive protein; LAD, left atrial diameter; AF, atrial fibrillation; SD, standard deviation. 
Table 3 Predictors of presence of long-standing AF in logistic regression analysis

\begin{tabular}{|c|c|c|c|c|}
\hline \multirow[t]{2}{*}{ Variable } & \multicolumn{2}{|l|}{ Univariate } & \multicolumn{2}{|l|}{ Multivariate } \\
\hline & OR $(95 \% \mathrm{Cl})$ & $P$ & OR $(95 \% \mathrm{Cl})$ & $P$ \\
\hline Age & $1.040(1.02 I-1.058)$ & $<0.001$ & I.02I (0.997-I.045) & 0.090 \\
\hline Smoke & $0.928(0.644-1.336)$ & 0.687 & $0.956(0.570-1.603)$ & 0.864 \\
\hline Hypertension & $1.055(0.689-1.6 \mid 4)$ & 0.806 & 1.117 (0.634-I.969) & 0.701 \\
\hline Dyslipidemia & $0.99 \mid(0.682-1.440)$ & 0.963 & 0.897 (0.538-I.497) & 0.687 \\
\hline Diabetes mellitus & I.28I (0.868-I.892) & 0.212 & I.662 (0.352-7.845) & 0.521 \\
\hline Cerebral infarction & I.327 (0.898-I.96I) & 0.156 & $0.592(0.123-2.844)$ & 0.513 \\
\hline Hematencephalon & $0.890(0.283-2.802)$ & 0.843 & $2.805(0.184-42.752)$ & 0.458 \\
\hline Family history of AF & $0.736(0.269-2.017)$ & 0.551 & $0.458(0.042-5.020)$ & 0.523 \\
\hline Arteriosclerosis & 1.351 (0.9|7-I.99I) & 0.128 & I.563 (0.943-2.592) & 0.083 \\
\hline $\mathrm{HR}>100 \mathrm{bpm}$ & $2.492(1.310-4.742)$ & 0.005 & $1.927(0.807-4.602)$ & 0.140 \\
\hline NEU $>8 \times 10^{9} / \mathrm{L}$ & $5.730(3.192-10.285)$ & $<0.001$ & $4.863(2.338-10.113)$ & $<0.001$ \\
\hline LAD >36 mm & $2.40 \mathrm{I}(\mathrm{I} .656-3.48 \mathrm{I})$ & $<0.001$ & $2.469(1.526-3.996)$ & $<0.001$ \\
\hline $\mathrm{Hs}-\mathrm{CRP}>5 \mathrm{mg} / \mathrm{L}$ & $2.069(1.338-3.201)$ & 0.001 & $2.458(1.406-4.298)$ & 0.002 \\
\hline $\mathrm{Hp} \delta$ value $\geq 4 \%$ 。 & II.724 (7.435-|8.487) & $<0.001$ & $13.172(7.819-22.191)$ & $<0.001$ \\
\hline $\mathrm{HCY} \geq 15 \mu \mathrm{mol} / \mathrm{L}$ & $2.902(1.993-4.226)$ & $<0.001$ & $3.203(1.983-5.173)$ & $<0.001$ \\
\hline
\end{tabular}

Abbreviations: AF, atrial fibrillation; OR, odds ratio; $\mathrm{Cl}$, confidence interval; $\mathrm{HR}$, heart rate; NEU, neutrophil; LAD, left atrial diameter; hs-CRP, high sensitive C-reactive protein; Hp, Helicobacter pylori; HCY, homocysteine.

current $\mathrm{Hp}\left({ }^{13} \mathrm{C}\right.$ urea breath test-negative), and current $\mathrm{Hp}$ (by the breath test). It was found that Hp-positive (by both tests) had a higher rate of long-standing AF than other two groups (short-standing AF group and control group), which indicated that the continuing action of chronic inflammation played an important role in the persistence of AF.

In our study, patients with $\mathrm{AF}$ were divided into five groups according to the classification of AF types in the 2012 European Society of Cardiology guidelines, and another classification was based on whether $\mathrm{AF}$ was persistent for more than 1 year. The study adopted ${ }^{13} \mathrm{C}$ urea breath test to test situation of Hp infection, considering LAD, the level of hs-CRP, and other relevant clinical data, and further analyzed the correlation between Hp infection and AF. Our study found that there was a significant correlation between $\mathrm{Hp} \delta$ value in the five groups. Patients with permanent AF in Group 5 had a higher level of Hp value than those in other groups. Patients with long-standing

Table 4 Contingency table for Hosmer and Lemeshow test

\begin{tabular}{|c|c|c|c|c|}
\hline \multicolumn{2}{|c|}{ Short-standing AF } & \multicolumn{2}{|c|}{ Long-standing AF } & \multirow[t]{2}{*}{ Total } \\
\hline Observed & Expected & Observed & Expected & \\
\hline 58 & 59.175 & 2 & 0.825 & 60 \\
\hline 57 & 57.403 & 2 & 1.597 & 59 \\
\hline 58 & 56.585 & 1 & 2.415 & 59 \\
\hline 52 & 55.124 & 7 & 3.876 & 59 \\
\hline 53 & 52.693 & 6 & 6.307 & 59 \\
\hline 50 & 48.439 & 9 & $10.56 \mid$ & 59 \\
\hline 45 & 41.317 & 15 & 18.683 & 60 \\
\hline 32 & 30.481 & 27 & 28.519 & 59 \\
\hline 17 & 18.094 & 42 & 40.906 & 59 \\
\hline 4 & 6.689 & 48 & 45.311 & 52 \\
\hline
\end{tabular}

Abbreviation: $\mathrm{AF}$, atrial fibrillation.
AF had a higher Hp value than those with short-standing AF. After adjusting for other important covariates in a multivariate regression model, $\mathrm{Hp} \delta$ value $\geq 4 \%$ remained an independent predictor for long-standing AF. ${ }^{13,14}$

More and more evidence has shown that inflammation reaction has been closely related to AF since 1997. Inflammation and $\mathrm{AF}$ are inseparable and have interaction and reciprocal causation, although whether the inflammation is the inducement or the secondary outcome of AF has not been determined. ${ }^{13} \mathrm{CRP}$ is recognized as one of the markers of inflammation. Some researchers have shown that CRP is one of the independent risk factors of AF, baseline CRP level can predict the risk of $\mathrm{AF}$ in the future, and CRP can reflect the degree of inflammation, which is closely related to the type and the duration of AF. ${ }^{14}$ Our study found that hs-CRP significantly increased in patients with long-standing $\mathrm{AF}$, which was consistent with the results of previous research. ${ }^{13,14}$

The core part of the development of AF is atrial remodeling, which includes electrical remodeling, functional remodeling, and structural remodeling. Atrial electrical remodeling in patients with long-standing AF is chronic and irreversible, which results in substantial calcium influx, calcium overload, atrial systolic dysfunction, atrial passive extension, and atrial enlargement and further aggravates the functional remodeling and structural remodeling. The three different remodelings reinforce each other in a vicious cycle. ${ }^{13,14}$ The longer the duration of $\mathrm{AF}$, the more obvious the atrial electrical remodeling and structural remodeling. Therefore, the LAD of patients with long-standing AF was significantly larger than those with short-standing AF in our study. 


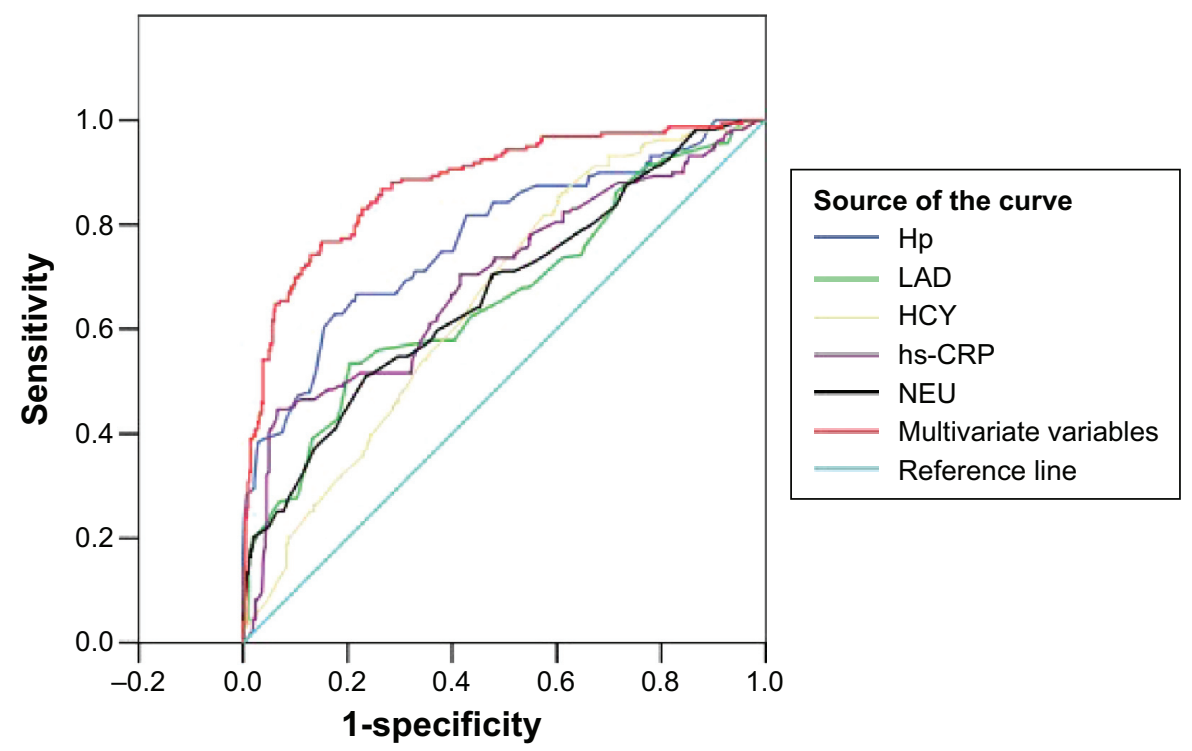

Figure 3 The ROC curves analysis of Hp infection, LAD, NEU, hs-CRP, HCY, and multivariate variables for predicting long-standing AF. Abbreviations: ROC, receiver-operating characteristic; Hp, Helicobacter pylori; LAD, left atrial diameter; NEU, neutrophil; hs-CRP, high sensitive C-reactive protein; HCY, homocysteine; $A F$, atrial fibrillation.

Our study found that the Hp value was significantly increased in patients with long-standing AF. Since inflammation is closely related to AF and Hp infection can lead to chronic inflammation, thus, it is reasonable to believe that there may be some internal relations between $\mathrm{Hp}$ infection and AF. On one hand, if patients are infected with $\mathrm{Hp}$, their bodies will produce $\mathrm{H}^{+} / \mathrm{K}^{+}$-ATP enzyme autoantibodies that bind to the $\mathrm{H}^{+} / \mathrm{K}^{+}$-ATP enzyme and then damage the atrial cell pump that makes the ion environment imbalanced and the depolarization delayed, which will trigger attack of $\mathrm{AF}^{7}$ On the other hand, Hp will produce cytotoxin-associated protein A (CagA), which will stimulate gastric epithelial cells to produce interleukin-8, induce NEU infiltration, and result in a series of inflammatory reactions. The longer the Hp infection lasts, the greater the CagA toxicity will be sustained and the more severe the atrial muscle cells will be damaged. ${ }^{15}$ This long-term chronic persistent inflammation is likely to be the foundation of permanent and long-term persistent AF.
The current study also found that Hp-IgG antibodies (which only shows that people were infected with Hp previously) had no correlation with the duration of $\mathrm{AF}$, which also proved the important role of the continuing action of chronic inflammation in the development of AF.

Although the study found Hp infection had a correlation with the duration of $\mathrm{AF}$, it could not confirm that $\mathrm{Hp}$ infection induced the long-term AF. So there is the possibility of reverse causality - individuals with AF, particularly longterm AF, are more susceptible to Hp infection and/or higher values of $\mathrm{Hp}$ infection.

\section{Limitations}

However, the study had some limitations. On one hand, this study is a retrospective research and has a small sample size. At the other hand, it did not provide detailed information on socioeconomic status because education and income are generally associated with $\mathrm{Hp}$ infection and low socioeconomic

Table 5 AUC, Se, and Sp

\begin{tabular}{|c|c|c|c|c|c|}
\hline \multirow[t]{2}{*}{ Test result variable } & \multicolumn{2}{|l|}{ Area under curve } & \multirow[t]{2}{*}{ Se $(95 \% \mathrm{CI})$} & \multirow[t]{2}{*}{ Sp $(95 \% \mathrm{CI})$} & \multirow{2}{*}{$\begin{array}{l}\text { The best } \\
\text { critical value }\end{array}$} \\
\hline & AUC ( $95 \% \mathrm{Cl})$ & $P$-value & & & \\
\hline Multivariate variables & $0.879(0.847-0.912)$ & $<0.001$ & $0.767(0.733-0.80 \mathrm{I})$ & $0.850(0.82 \mathrm{I}-0.879)$ & 0.359 \\
\hline Hp $\delta$ value \%。 & $0.774(0.729-0.820)$ & $<0.001$ & $0.667(0.629-0.705)$ & $0.784(0.75 \mathrm{I}-0.8 \mathrm{I} 7)$ & 14.75 \\
\hline NEU $\left(10^{9} / \mathrm{L}\right)$ & $0.669(0.619-0.720)$ & $<0.001$ & $0.509(0.468-0.550)$ & $0.765(0.73 \mathrm{I}-0.799)$ & 6.25 \\
\hline $\mathrm{HCY}(\mu \mathrm{mol} / \mathrm{L})$ & $0.655(0.608-0.702)$ & $<0.001$ & $0.54 \mathrm{I}(0.50 \mathrm{I}-0.58 \mathrm{I})$ & $0.657(0.619-0.695)$ & 12.52 \\
\hline hs-CRP (mg/L) & $0.694(0.643-0.745)$ & $<0.001$ & $0.447(0.407-0.487)$ & $0.934(0.914-0.954)$ & 21.15 \\
\hline LAD (mm) & $0.662(0.6|0-0.7| 4)$ & $<0.001$ & $0.535(0.495-0.575)$ & $0.796(0.763-0.829)$ & 37.10 \\
\hline
\end{tabular}

Abbreviations: AUC, area under curve; Se, sensitivity; Sp, specificity; Cl, confidence interval; Hp, Helicobacter pylori; NEU, neutrophil; HCY, homocysteine; hs-CRP, high sensitive C-reactive protein; LAD, left atrial diameter. 
status may also be associated with AF, although all the subjects came from the same community. Large prospective studies are expected to confirm what we found in the relationship between Hp infection and long-standing AF.

\section{Disclosure}

The authors declare ethical adherence and that they have no conflicts of interest.

\section{References}

1. Zeng Y, Cui Y, Li Y, et al. Recurrent atrial arrhythmia after minimally invasive pulmonary vein isolation for atrial fibrillation. Ann Thorac Surg. 2010;90:510-515.

2. Hermida J, Lopez FL, Montes R, Matsushita K, Astor BC, Alonso A. Usefulness of high-sensitivity $\mathrm{C}$-reactive protein to predict mortality in patients with atrial fibrillation (from the Atherosclerosis risk in communities [ARIC] Study). Am J Cardiol. 2012;109:95-99.

3. Huang GD, Huang YH, Xiao MZ, Huang DF, Liu J, Li JB. Effect of volatile oil of amomum on expressions of platelet activating factor and mastocarcinoma-related peptide in the gastric membrane of chronic gastritis patients with helicobacter-pylori infection. Chin J Integr Med. 2008;14:23-27.

4. Andrew P, Montenero AS. Is Helicobacter pylori a cause of atrial fibrillation? Future Cardiol. 2006;2:429-439.

5. Bunch TJ, Day JD, Anderson JL, et al. Frequency of Helicobacter pylori seropositivity and C-reactive protein increase in atrial fibrillation in patients undergoing coronary angiography. Am J Cardiol. 2008;101: 848-851.

6. Montenero AS, Mollichelli N, Zumbo F, et al. Helicobacter pylori and atrial fibrillation: a possible pathogenic link. Heart. 2005;91: 960-961.
7. Badran HM, Mahfouz ME. Cytotoxin-associated gene-A bearing strains of Helicobacter pylori and atrial fibrillation due to ischemic origin: is there a link? Eur J Cardiovasc Prev Rehabil. 2007;14:518-520.

8. Ki MR, Shin DG, Park JS, et al. Frequency of vacuolating cytotoxin A (VacA)-positive Helicobacter pylori seropositivity and TGF- $\beta 1$ decrease in atrial fibrillation. Int $J$ Cardiol. 2010;145:345-346.

9. Lunetta M, Fazio G, Avena V, et al. Helicobacter pylori and atrial fibrillation: absence of correlations. $J$ Cardiovasc Med (Hagerstown). 2009;10:4-5.

10. Platonov P, Ekesbo R, Hansson A, et al. Permanent atrial fibrillation in patients without structural heart disease is not associated with signs of infection by Chlamydia pneumoniae and Helicobacter pylori. Acta Cardiol. 2008:63:479-484.

11. Camm AJ, Lip GY, De Caterina R, et al; ESC Committee for Practice Guidelines-CPG; Document Reviewers. 2012 focused update of the ESC Guidelines for the management of atrial fibrillation: an update of the 2010 ESC Guidelines for the management of atrial fibrillation developed with the special contribution of the European Heart Rhythm Association. Europace. 2012;14:1385-1413.

12. Chung MK, Martin DO, Spreeher D. C-reactive protein elevation in patients with atrial arrhythmias: inflammatory mechanisms and persistence of atrial fibrillation. Circulation. 2001;104:2886-2891.

13. Pirat B, Atar I, Ertan C, et al. Comparison of C-reactive protein levels in patients who do and do not develop atrial fibrillation during electrophysiologic study. Am J Cardiol. 2007;100:1552-1555.

14. Sharma D, Li G, Xu G, Liu Y, Xu Y. Atrial remodeling in atrial fibrillation and some related microRNAs. Cardiology. 2011;120:111-121.

15. Schimke K, Chubb SA, Davis WA, Davis TM. Helicobacter pylori cytotoxin-associated gene-A antibodies do not predict complications or death in type 2 diabetes: the Fremantle Diabetes Study. Atherosclerosis. 2010;212:321-326.
Clinical Interventions in Aging

\section{Publish your work in this journal}

Clinical Interventions in Aging is an international, peer-reviewed journal focusing on evidence-based reports on the value or lack thereof of treatments intended to prevent or delay the onset of maladaptive correlates of aging in human beings. This journal is indexed on PubMed Central, MedLine,

\section{Dovepress}

CAS, Scopus and the Elsevier Bibliographic databases. The manuscript management system is completely online and includes a very quick and fair peer-review system, which is all easy to use. Visit http://www.dovepress. com/testimonials.php to read real quotes from published authors. 